\title{
Towards the Development of Mobile App Design Model for Dyscalculia Children in Malaysia
}

\author{
Fiqa Azureen Abd Halim, ,*, Mazeyanti Mohd Ariffin², \& Savita K. Sugathan ${ }^{3}$ \\ 1, 2,3 Computer \& Information Sciences Department, Universiti Teknologi Petronas, Malaysia
}

\begin{abstract}
Learning disabilities (LD) are problem that influence the brain capacity to receive, process, analyse and store information. These processing issues can interfere with learning fundamental abilities, for example, reading (Dyslexia), writing (Dysgraphia) and math (Dyscalculia). Fortunately, in today's world technology, we have numerous option techniques for educating and supporting fundamental skills in reading, writing and math such as mobile learning by using mobile app. However, the research in mobile app design model for Dyscalculia children is still scarce: very few studies have focus on how to design and develop appropriate mobile app for Dyscalculia children from the perspective of mobile app designers and developers. The purpose of this paper is to identify the appropriate components that should be included in the mobile app model. Interview sessions were conducted with Dyscalculia practitioners that involved a teacher, paediatric and an educational psychology. This has resulted in identifying 16 components that can be included in the mobile app design model.
\end{abstract}

\section{Introduction}

According to Malaysian Ministry of Education (2016), 29810 primary school children are known to enrol in special education integration program including learning disability (LD). In Malaysia, LD is included Dyslexia, Dyscalculia and Dysgraphia (Malaysian Social Welfare Department, 2016). LD is neurologically-based processing issues (Butterworth, 2013). These processing issues can meddle with learning essential aptitudes, for example, reading, writing and math. LD is a wide term depicting various others, more particular learning disability such as Dyslexia which refers to difficulty in reading, Dysgraphia refers to difficulty in writing and Dyscalculia refers to difficulty in math.

Nowadays, a lot of technologies have been developed and some of them can help the children with LD such as mobile app. According to Skiada, Soroniati, Gardeli, \& Zissis, (2014), the advantages of utilizing mobile learning are to create interactive encounters and idealistic learning surroundings that can motivate and help children, along these lines offering them some assistance with addressing their disabilities in early age and potentially alleviate its negative impacts' differences. However, the research on the mobile app design model is still limited (Ok, Kim, Kang, \& Bryant, 2016). Thus, the mobile app designer and developer is lacking of guidance on how to design appropriate mobile app for LD children (Draper Rodriguez, Strnadova, \& Cumming, 2014). Hence, the objective of this research is to identify the potential components that can be included in the mobile app design model called Calculic Model.
As mentioned before, the designers and developers of mobile app are lacking of guidance to design and develop the effective mobile app particularly for teaching and learning for LD children (Draper Rodriguez et al., 2014). As a result, most of the mobile app for LD children are poorly designed (Papadakis, Kalogiannakis, $\&$ Zaranis, 2017). To address this issue, the purpose of this study is to develop a Calculic Model that can guide mobile app designers and developers in designing and developing mobile app for Dyscalculia children. In order to design and develop an effective mobile app for LD children, the developer and designer of mobile app should follow the model and guideline from the researchers and teachers (Cumming, Strnadov, \& Singh, 2014). Hence, the interview session with Dyscalculia practitioners have been conducted to identify the appropriate components in Calculic Model for Dyscalculia children in teaching and learning.

\section{Literature Review}

\subsection{Learning Disability}

Dyslexia is a type of LD particularly in reading. According to Nayton, Hettrich, Samar, \& Wilkinson (2017), Dyslexia alludes to a group of symptoms', which result in individuals experiencing issues with particular language abilities, especially reading. Children with Dyslexia usually encounter troubles with other language aptitudes, for example, spelling, writing, and professing words. British Dyslexia Association claims that Dyslexia

\footnotetext{
* Corresponding author: fiqazureen@gmail.com
} 
frequently happens in association with the other formative disorder, such as Dyscalculia and Dysgraphia.

According to Drigas, Pappas, \& Lytras (2016), children with Dyscalculia often have difficulties in number processing and basic math operation such as addition, subtraction, multiplication and division. Dysgraphia is a learning disability that related to writing difficulties. Dysgraphia was initially incorporated into the depiction of Dyslexia however is presently separated as a component inside the wide range of writing issue, alluding particularly to spelling, and indecipherable handwriting (Fletcher-Flinn, 2016).

Cortiella \& Horowitz (2014) estimated that 2.4 million of American public schools' students were identified with LD. $66 \%$ of students identified with LD are male. Meanwhile, the percentage of female students with LD is about $51 \%$ (Cortiella \& Horowitz, 2014). The male students are more likely to be diagnosed with the LD as compared to the female students.

\subsection{Dyscalculia}

Dyscalculia is induced at first as a persevering trouble in the learning or comprehension of number such as knowing fundamental number names, segregating the bigger or smaller number, counting number sequence, and troubles in basic math operation (Plerou, 2014). Research by Renwick (2014) found that possible indicators of Dyscalculia are numeric issues, spatial issues, memory issues and measure issue. Table 1 shows the early signs of Dyscalculia by Plerou (2014).

Table 1. Signs of Dyscalculia.

\begin{tabular}{|l|l|}
\hline \multicolumn{2}{|c|}{ Signs of Dyscalculia } \\
\hline $\begin{array}{l}\text { Difficulties in basic number } \\
\text { counting }\end{array}$ & $\begin{array}{l}\text { Unable to memorize the } \\
\text { number sequence }\end{array}$ \\
\hline $\begin{array}{l}\text { Difficulties in determine } \\
\text { which objects are bigger or } \\
\text { smaller }\end{array}$ & $\begin{array}{l}\text { Difficulties in objects } \\
\text { counting }\end{array}$ \\
\hline $\begin{array}{l}\text { Difficulties in connecting the } \\
\text { number concept to the } \\
\text { symbolic form (example: 5 } \\
\text { five) }\end{array}$ & $\begin{array}{l}\text { Difficulties in number } \\
\text { amparison which numbers } \\
\text { are bigger or smaller }\end{array}$ \\
\hline $\begin{array}{l}\text { Poor in sense direction such } \\
\text { as right or left. }\end{array}$ & Difficulties in clock reading. \\
\hline
\end{tabular}

According to Morin (2014) the children with Dyscalculia show different signs at different age and Dyscalculia tend to be more visible as children get older. However, it can be recognized as early as preschool. Dyscalculia can be detected at an early age by difficulties noticed in calculating the quantity of objects, in counting and in the recognition of the mathematical operations symbol (Plerou, 2014). British Dyslexia Association claims that Dyscalculia frequently happens in association with the other formative disorder, such as Dyslexia and Dysgraphia.

\subsection{Mobile Learning \& Dyscalculia}

Mobile learning might be favoured by children, as it can possibly provide an extensive variety of function and segments which offer an exceptionally intelligent learning background. (Skiada et al.,2014). Dyscalculia children should utilize the mobile learning to make learning easier and easy to adapt this method of learning (Mulligan, 2012). Mobile apps have potential in education due to the graphic and sound that can help them to stimulate their brain to learn math effectively and grab the concept quickly (Nagavalli \& Juliet, 2015).

A study conducted by Mohd Ariffin, Abd Halim \& Abd Aziz (2017) reported that learning through mobile app show positive improvement for Dyscalculia children in math learning.

\subsection{Initial Calculic Model}

A study conducted by Abd Halim, K. Sugathan \& Mohd Ariffin (in press), illustrated the initial Calculic Model that comes from the literature review. They have extended the components in the instructional factor by adding one new component which is language. Vukovic \& Lesaux (2013) supported that language has a relationship in learning and teaching Maths and language also relate to Dyscalculia children mathematical performance. Language is important for the development of mathematical proficiency (Vukovic \& Lesaux, 2013). Figure 1 shows initial Calculic Model.

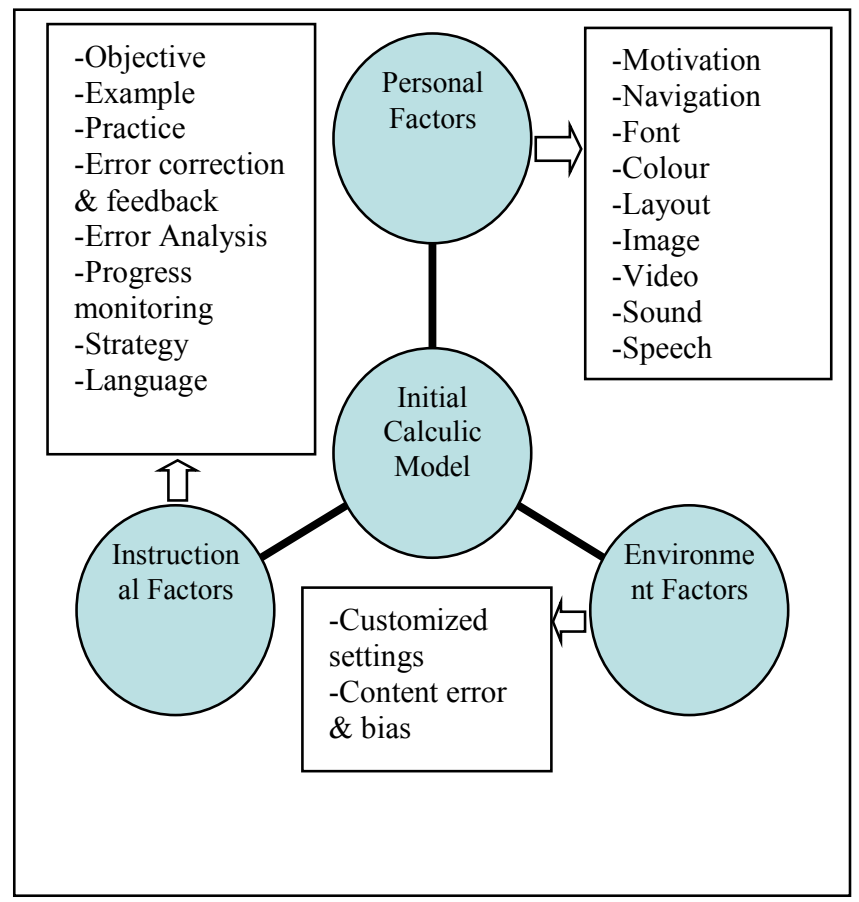

Figure 1. Initial Calculic Model.

The initial Calculic model has three 3 factors which are instructional factor, personal factor and environment factor. There are 8 components under the instructional strategic factor which are 'objective', 'strategy', 'example', 'practice', 'error correction and feedback', 'error analysis', 'progress monitoring', and 'language'. Meanwhile, there are 9 components that fall in personal factor which are 'motivation', 'navigation', 'font', 'color', 'layout', 'image', 'video', 'sound' and 
'speech'. There are 2 components under the environment factor which are 'customized settings' and 'content error and bias'.

Besides that, the presentation style is very important because inappropriate presentation layout can be confusing particularly when the text is written too close (Chinn \& Ashcroft, 2017). According to Chinn \& Ashcroft (2017), most of the mobile apps use a crowded layout and it is very difficult for Dyscalculia children to read the information in the correct order. Thus, this kind of presentation can distract Dyscalculia children. Drigas \& Kokkalia (2016); Weng \& Taber-Doughty (2015), proposed to use clear, simple and consistent layout design so that Dyscalculia children can navigate the app easier. The layout design should avoid cramping material, use short text and numbering or bullet point (Aziz, Husni \& Jamaludin, 2013). Hence, Calculic Model have included the 'layout' component to support learning for Dyscalculia children.

\section{Methodology}

As a preliminary study, an interview session was conducted with Dyscalculia practitioners that involved a teacher, paediatrician and educational psychology in order to support the components that come from literature review. The interview session was aimed to review the initial Calculic model that come from literature review. The interview session was conducted to gather information about Dyscalculia children, the appropriate method to teach them, and how to design an effective mobile app for Dyscalculia children.

\subsection{Participants}

Three Dyscalculia practitioners were recruited. The number of Dyscalculia practitioner in Malaysia is very limited. All the participants have more than 5 years' of experiences in handling Dyscalculia children. The details of the participants are shown in Table 2 .

Table 2. Details of Participants.

\begin{tabular}{|l|l|l|}
\hline $\begin{array}{l}\text { Participant } \\
\text { ID }\end{array}$ & Profession & $\begin{array}{l}\text { Years of } \\
\text { Experience }\end{array}$ \\
\hline P1 & $\begin{array}{l}\text { Educational } \\
\text { psychology }\end{array}$ & 17 years \\
\hline P2 & Pediatrician & 15 years \\
\hline P3 & Teacher & 7 years \\
\hline
\end{tabular}

Hence, the role of P1 is to assess the difficulty of Dyscalculia children in learning and suggested the methods or strategies that can help Dyscalculia children in learning based on their cognitive style and behavioural. The main role of $\mathrm{P} 2$ is to do physical examinations to the children and diagnose the children with Dyscalculia. Thus, the main role of P3 is to teach Dyscalculia children particularly in maths. All the participants have different role in their profession.

\subsection{Instruments}

The author conducted face to face semi structured interview with P2 and P3. Meanwhile, the interview session with P1 was conducted via telephone. Each interview took between 45 minutes to 80 minutes. Participants were asked about: (1) their experience in handling Dyscalculia children; (2) to describe how they teach the Dyscalculia children and (3) what components or features that suitable for Dyscalculia children in learning. The main questions in the interview guide comprise:

1. How was your experience in handling Dyscalculia children?

2. How to teach Dyscalculia children in math learning?

3. What are the potential components that should have if you want to design mobile app for Dyscalculia children for math learning?

All of the components were probed with more specific questions and in depth discussion during interviews to understand which components are important for Dyscalculia children during learning through mobile app and how to design for each component.

\subsection{Data Analysis}

The data from the interview session were transcribed verbatim with consent. The data were analyzed to find which components are most important and which components are least important.

\section{Results \& Discussion}

Dyscalculia children are different from normal children. As mentioned earlier, they have troubles in understanding numerical concept. Thus, they have different style of learning and it is crucial to identify the appropriate teaching strategy for Dyscalculia children.

\subsection{Participants Perspective on Dyscalculia}

Based on the interview session with Dyscalculia practitioners that involved educational psychology, paediatrician and a teacher, they found out that Dyscalculia children are special need children that have different learning style compared to the normal children. From the interview session, all the participants talked about multisensory approach. They agreed that multisensory approach is one of the teaching strategies for Dyscalculia children. The multisensory learning involved auditory, visual, tactile and kinaesthetic. The multisensory learning strategy can be applied in mobile app. Moreover, the multisensory approach is proven to be an effective teaching approach for Dyscalculia children (Duijzer, Shayan, Bakker, Van der Schaaf, \& Abrahamson, 2017).

Based on the interview, Dyscalculia children can be cured if the teaching strategy is suitable for them in math learning. According to $\mathrm{P} 3$, the teaching material should be appropriate for Dyscalculia children because they 
require an appropriate learning material that can empower their motivation in learning. For example, the use of graphics and sounds in the mobile app can motivate them in math learning.

According to $\mathrm{P} 1$, the cognition style and the behavioural of Dyscalculia children are the important aspects that need to be identified before developing any learning material or tools. Usually the Dyscalculia children have major difficulties in memory and numerical processing.

According to P2, parents should be aware of the signs shown by their children at the early age because LD can be diagnosed as early as 6 years old. However, in Malaysia, most of the children are diagnosed at 7 years old. Hence, the intervention steps at the early age are crucial because the intervention is likely to be more effective.

\subsection{Analysis of the Interview}

From the interview session, preliminary analyses were performed to the collected data. Table 3 shows the analysis of the interview.

Table 3. Analysis from Interview

\begin{tabular}{|c|c|c|c|c|}
\hline No & Components & $\mathrm{P} 1$ & $\mathrm{P} 2$ & P3 \\
\hline 1 & Motivation & 7 & $\mathrm{x}$ & I \\
\hline 2 & Navigation & 7 & 1 & 1 \\
\hline 3 & Font & l & I & 1 \\
\hline 4 & Colour & 7 & / & 1 \\
\hline 5 & Layout & 7 & / & 1 \\
\hline 6 & Images & 1 & / & I \\
\hline 7 & Video & 7 & 1 & 1 \\
\hline 8 & Sound & 1 & I & 1 \\
\hline 9 & Speech & 7 & / & I \\
\hline 10 & Objective & 7 & / & I \\
\hline 11 & Examples & 7 & I & 1 \\
\hline 12 & Practice & 7 & / & 1 \\
\hline 13 & $\begin{array}{l}\text { Error correction \& } \\
\text { feedback }\end{array}$ & / & / & I \\
\hline 14 & Error analysis & 1 & $\mathrm{x}$ & $\mathrm{x}$ \\
\hline 15 & Progress monitoring & 7 & 1 & 1 \\
\hline 16 & Strategy & $\mathrm{x}$ & $\mathrm{x}$ & $\mathrm{x}$ \\
\hline 17 & Language & 1 & I & 1 \\
\hline 18 & Customized setting & $\mathrm{x}$ & 1 & $\mathrm{x}$ \\
\hline 19 & Content error \& bias & $T$ & 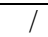 & 1 \\
\hline
\end{tabular}

Based on the initial analysis shown in Table 3, there are 3 components that need to be eliminated from the proposed model which are 'error analysis', 'strategy' and 'customized setting'. The components were eliminated based on the majority from the participants.

\subsubsection{Error Analysis}

Two participants (P2 and P3), both agreed that 'error analysis' is not necessary to include in the model.

P2 said:

"It is not necessary to include error analysis in the mobile app. I think it is not important to keep record of the children error because this will make them demotivated"

Meanwhile, P3 said:

"It is not necessary because if they get incorrect answer they can repeat the same question until they get correct answer. They can do the same question in order to make them more understand"

\subsubsection{Strategy}

All the participants gave opinion that 'strategy' component can be eliminated from the initial Calculic Model. P1 said:

"The strategy can be used in examples such as show step by step example, break down small part, show step by step"

P2 said:

"Not necessary to include strategy because mobile app should know the appropriate strategy to be used to teach them. I think you can use a multisensory strategy in example and practice"

Meanwhile P3 said:

"The strategy should be include in the practice component such as give them hint for correct answer"

\subsubsection{Customized Settings}

Two participants (P1 and P3), gave opinion that 'customized setting' component is not necessary to include in the model. P1 said:

"It is not necessary. The target user is Dyscalculia children so just design specific to them"

Meanwhile P3 said:

"It is not necessary because the design of mobile app should be appropriate so that they can learn effectively without need to change anything"

\subsection{Proposed Calculic Model}

The Figure 2 shows the proposed Calculic Model after the elimination of 3 components. 


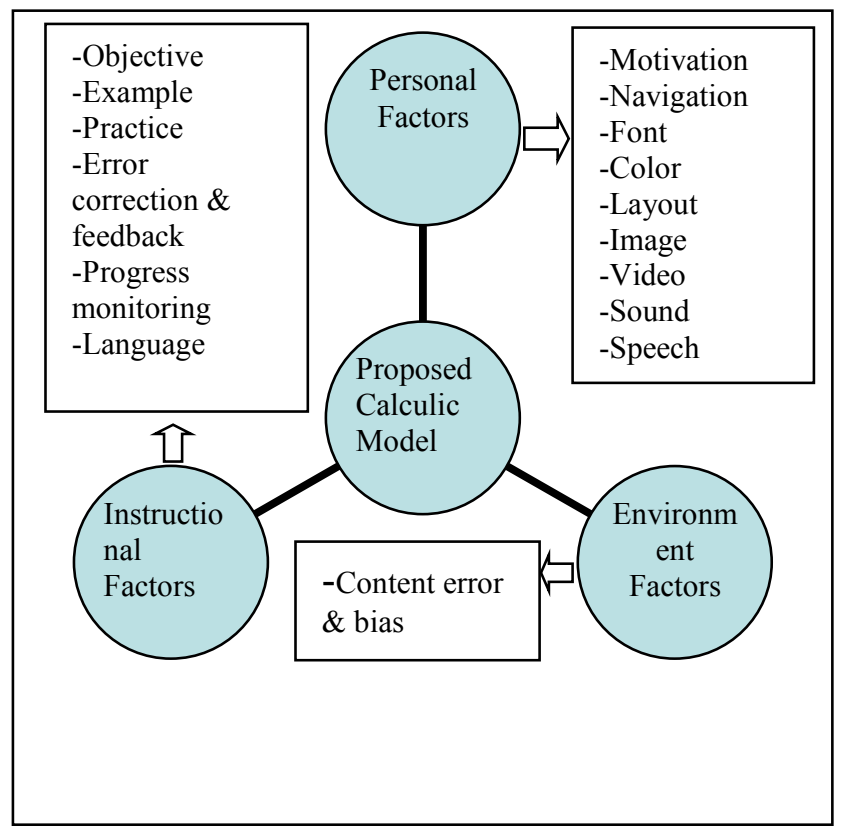

Figure 2. Proposed Calculic Model

Three components have been eliminated from the initial Calculic model. The proposed Calculic model has three 3 factors which are instructional factor, personal factor and environment factor. There are 6 components under the instructional strategic factor which are 'objective', 'example', 'practice', 'error correction and feedback', 'progress monitoring', and 'language'. Meanwhile, there are 9 components that fall under personal factor which are 'motivation', 'navigation', 'font', 'color', 'layout', 'image', 'video', 'sound' and 'speech'. There are 1 components under the environment factor which is 'content error and bias'.

Based on Figure 2, there are 16 components that are important for Dyscalculia children in learning. For example, 'font' component in personal factor is important because the font can influent their reading performance and word understanding (Rello \& BaezaYates, 2013). Moreover, from the interview session, all the participants agreed that the font component is important. P1 said:

"The font is important and the font chosen should be suitable with Dyscalculia children and also readable"

While P2 said:

"The font is important component that should be include in the mobile app. I think the suitable font is Arial type font"

\section{P3 said:}

"The font is very important components that mobile app should include because the font can affect their reading. The suitable font should be non-serif font"

Moreover, Rello \& Baeza-Yates (2013), reported that the san serif font and roman style lead to better readability to LD children. Research by Brittany \& Ross, (2015), supported that the san serif category font is suitable for Dyscalculia children because the font is readable for Dyscalculia children. Thus, this research aimed to include font as one of the components to support learning for Dyscalculia children.

Besides, the 'practice' component in instructional factor is also important. Thus, practice should provide clear and consistent guidance for Dyscalculia children because they need sufficient practice to enhance deeper learning (OK \& Bryant, 2015). From the interview session, all the participants agreed that practice is important that should be included in the model. P1 said:

"Practice is important in learning process. Practice should have a level of difficulty"

P2 said:

"The practice should be include in the mobile app so that they can try the practice after they have learn through example"

Meanwhile P3 said:

"The practice is important because it is the part of learning process. Provide them a guidance in doing the practice"

In addition, a study conducted by Mohd Ariffin, Abd Halim \& Abd Aziz (2017) reported that guidance elements such as providing hint through font colour in the practice can encourage them to choose the correct answer. Hence, this research aimed to include 'practice' as one of the components to support learning for Dyscalculia children.

Next is the 'content error and bias' component in environment factor. According to Bryant, Bryant, \& Pfannenstiel (2015) leaning material is prohibited for content error because incorrect example or misstated formula can lead to confusion. The effective content of mobile app for Dyscalculia children is free from error, up-to-date and free from bias (Ok, Kim, et al., 2016). From the interview session, P1 said:

"Any learning material should free from bias and error. That's the good feature of any learning material"

P2 said:

"Content in the mobile app should be free from error and bias because they need an appropriate learning material in learning"

Meanwhile, P3 said:

"It is important that the mobile app should be free from error and bias to avoid the confusion"

The effective content of mobile app for Dyscalculia children is free from error, up-to-date and free from bias (Ok, Kim, et al., 2016). Thus, this research aimed to include content error and bias as one of the components to support learning for Dyscalculia children.

\section{Conclusion \& Future Work}

This paper presented the development of the mobile app design model called Calculic Model. As mentioned earlier, the Calculic Model is for mobile app designers and developers to design and develop an appropriate 
mobile app for Dyscalculia children in Malaysia. An interview session was conducted with Dyscalculia practitioners that involved a teacher, paediatrician and an educational psychology to review the components of initial Calculic Model. Initially there are 19 components in Calculic Model. As a result, there were 16 components included in the proposed Calculic Model. Hence, 3 components were eliminated which are 'error analysis', 'strategy' and 'customized setting'. For the future work, the proposed Calculic Model will be verified by mobile app designers and developers.

This research work is currently undertaken by Fiqa Azureen Abd Halim, Msc student in Information Technology at Universiti Teknologi Petronas.

\section{References}

1. Abd Halim, F. A., K Sugathan, S., \& Mohd Ariffin, M. (in press). Towards a Mobile App Design Model for Dyscalculia Children in Malaysia. In e-Learning, eManagement and e-Services (IC3e), 2017 IEEE Conference. IEEE.

2. Aziz, F. A., Husni, H., \& Jamaludin, Z. (2013). Translating interaction design guidelines for dyslexic children's reading application. In Proceedings of the World Congress on Engineering (Vol. 2).

3. Butterworth, B. (2013). Handbook of Mathematical Cognition: Chapter 26: Developmental Dyscalculia. Mathematical Cognition, 455-468.

4. Bryant, D. P., Bryant, B. R., \& Pfannenstiel, K. H. (2015). MathematicsInterventions: Translating Research Into Practice Mathematics Interventions : Translating Research Into Practice, (November). https://doi.org/10.1177/1053451214560893

5. Chinn, S. J., \& Ashcroft, R. E. (2017). Mathematics for dyslexics and dyscalculics: a teaching handbook. Chichester, West Sussex: Wiley Blackwell.

6. Cortiella C. \& Horowitz, S. H. The State of Learning Disabilities: Facts, Trends and Emerging Issues. New York: National Center for Learning Disabilities, 2014.

7. Cumming, T. M., Strnadová, I., \& Singh, S. (2014). IPads as instructional tools to enhance learning opportunities for students with developmental disabilities: An action research project. Action Research, 12(2), 151-176. doi: $10.1177 / 1476750314525480$

8. Duijzer, A. C. G. C., Shayan, S., Bakker, A., Van der Schaaf, M. F., \& Abrahamson, D. (2017). Touchscreen Tablets: Coordinating Action and Perception for Mathematical Cognition, 8(February), 1-19. https://doi.org/10.3389/fpsyg.2017.00144

9. Draper Rodriguez, C., Strnadova, I., \& Cumming, T. (2014). Using iPads With Students With Disabilities: Lessons Learned from Students, Teachers, and Parents. Intervention in School and Clinic, 49(4), 244-250. https://doi.org/10.1177/1053451213509488

10. Drigas, A., \& Kokkalia, G. (2016). Mobile Learning for Special Preschool Education. International Journal of Interactive Mobile Technologies (iJIM), 10(1), 67. doi:10.3991/ijim.v10i1.5288

11. Drigas, A., Pappas, M. ., \& Lytras, M. (2016). Emerging Technologies for ICT based Education for Dyscalculia: Implications for Computer Engineering Education. International Journal of Engineering Education, 32(4),
1604-1610. Retrieved from http://search.ebscohost.com/login.aspx?direct=true\&Auth Type $=\mathrm{ip}$, shib\&db=bri\&AN=117610015\&site $=$ ehostlive \&scope $=$ site

12. Fletcher-Flinn, C. M. (2016). Developmental Dysgraphia as a Reading System and Transfer Problem: A Case Study. Front. Psycho, 7(149). doi:10.3389/fpsyg.2016.00149

13. Mazeyanti Mohd Ariffin, Fiqa Azureen Abd Halim, \& Norshakirah Abd Aziz. (2017). Mobile application for dyscalculia children in Malaysia in Zulikha, J. \& N. H. Zakaria (Eds.), Proceedings of the 6th International Conference on Computing \& Informatics (pp 467-472). Sintok: School of Computing.

14. Morin, A. (2014, March 10). Understanding Dyscalculia. Retrieved February 21, 2016, from $\mathrm{https} / /$ www.understood.org/en/learning -attentionissues/child-learning disabilities/dyscalculia/understanding-dyscalculia

15. Nagavalli, T., \& Juliet, P. (2015). Technology For Dyscalculic Children. SALEM, 16, 1-10. Retrieved January 16, 2017

16. Nayton, M., Hettrich, E. L., Samar, S., \& Wilkinson, C. (2017). Evidence-Based Assessment and Interventions for Problems with Reading in School Psychology. In Handbook of Australian School Psychology (pp. 173195). Springer International Publishing

17. OK, M. W., \& Bryant, D. P. (2015). Effects of a Strategic Intervention With iPad Practice on the Multiplication Fact Performance of ... Effects of a Strategic Intervention With iPad Practice on the Multiplication Fact Performance of Fifth-Grade Students With Learning Disabilities, (August). https://doi.org/10.1177/0731948715598285

18. Ok, M. W., Kim, M. K., Kang, E. Y., \& Bryant, B. R. (2016). How to Find Good Apps: An Evaluation Rubric for Instructional Apps for Teaching Students With Learning Disabilities. Intervention in School and Clinic, 1053451215589179-.

https://doi.org/10.1177/1053451215589179

19. Papadakis, S., Kalogiannakis, M., \& Zaranis, N. (2017). Designing and creating an educational app rubric for preschool teachers. Education and Information Technologies. doi:10.1007/s10639-017-9579-0

20. Plerou, A. (2014). Dealing With Dyscalculia Over Time. Icicte, (2008), 1-12. https://doi.org/10.13140/2.1.4229.5681

21. Rello, L., \& Baeza-Yates, R. (2013). Good fonts for dyslexia. ASSETS 2013: Proceedings of the 15th International ACM SIGACCESS Conference on Computers and Accessibility, 1-8. https://doi.org/10.1145/2513383.2513447

22. Skiada, R., Soroniati, E., Gardeli, A., \& Zissis, D. (2014). EasyLexia: A Mobile Application for Children with Learning Difficulties. Procedia Computer Science, 27(Dsai 2013), 218-228. https://doi.org/10.1016/j.procs.2014.02.025

23. Vukovic, R. K., \& Lesaux, N. K. (2013). The language of mathematics: Investigating the ways language counts for children's mathematical development. Journal of Experimental Child Psychology, 115(2), 227-244. doi:10.1016/j.jecp.2013.02.002

24. Weng, P., \& Taber-Doughty, T. (2015). Developing an App Evaluation Rubric for Practitioners in Special Education. Journal of Special Education Technology, 30(1), 43-58. doi:10.1177/016264341503000104 